\title{
A Recipe for Heganism? Masculinity, Meat-Avoidance and the Cookbook
}

\author{
Rebecca Jones
}

\begin{abstract}
Veganism and plant-based diets have grown exponentially in popularity in the UK in recent years. Despite this overall growth in popularity, however, there remains a gender disparity amongst vegans, with men remaining under-represented amongst those identifying as vegan. The increased popularity of veganism and plant-based diets has both resulted in, and been boosted by, a recent surge in the number of vegan and plant-based cookbooks being published to the UK market. This article offers a qualitative textual analysis of three vegan and/or plant-based cookbooks by male authors published to the UK market in 2018. This analysis suggests new ways of thinking about the roles of food and diet in constructing and inscribing masculine identities, and the power that the vegan movement, in its broadest sense, has to either reify or challenge prescribed and restrictive masculinities as it seeks to promote veganism and plant-based diets.
\end{abstract}

KEYWORDS veganism, masculinity, cookery, feminism, recipes, diet, plant-based

\section{Introduction}

Veganism is not a recent concept. Plant-based diets and meat-avoidance are neither a twentyfirst century, nor a uniquely white or Eurocentric innovation (see for example Raet [2010] on the Ma'at diet, Fisher [2011] on Ojibway and Cherokee identity and veganism, Breeze Harper [2011] on veganism and racism, and Spencer [2016] and Stuart [2008] on the history of meat-avoidance). Likewise the cookbook is nothing new, with examples of the genre intended to instruct both in food preparation and gendered household norms dating from at least as early as the eighteenth century (Coghlan 2020; Neuhaus 2012). The 1950s postwar recalibrations of gender, work and the home led to the publication of many cookbooks aimed at advising women not just on how to cook, but on how to achieve broader household equilibrium by doing so (see for example Neuhaus 1999; Culver 2012). Just as veganism is not merely a twenty-first century trend, then, the cookbook has a history that pre-dates the modern age of cookery TV shows, and even entire channels dedicated to cookery. Celebrity chefs are instantly recognisable across media, publicising cookbooks, TV series and even personally-branded cookware by cultivating distinctive, often controversial personalities. UK consumer interactions with cookery across media are profoundly inflected by glossy product and aspirational celebrity identity. Cookbooks are centrally positioned within the multi-media cookery industry, and I suggest that they have more than enough

Sociálnístudia/Social Studies 2/2021.S.105-121.ISSN 1214-813X.https://doi.org/10.5817/SOC2021-2-105 
market significance both to respond to increasing demand and interest in culinary fashions and, crucially, to establish and create new iterations of that demand. As such, they are an illuminating object of analysis of how food and diet assist in constructing and actualising identity. In this article, I present a qualitative analysis of three examples of vegan and/or plant-based, male-authored cookbooks published to the UK market in 2018. This analysis will enable me to suggest some observations about the role of the male-authored vegan or plant-based cookbook in the UK media, and to draw some conclusions about the (vegan) masculinities that are being reflected, spoken to, and reinforced by vegan or plant-based cookbooks authored by men.

The persistent and pervasive perception of veganism as an essentially feminine concern, particularly in white, Western contexts, has been well established by feminist scholars including Adams (2015), Nath (2010) and Wright (2015). My textual analyses of the three examples cited in this article are indebted to this work on meat and masculinity. In addition to this work, I employ the theory of hegemonic masculinity put forward by Connell $(2000,2005)$ and Connell and Messerschmidt (2005) to analyse these texts, and to establish the ways in which they, whether deliberately or not, cooperate with hegemonic masculinity as it relates to food, cooking and eating, despite their focus on meat-avoidance as opposed to conspicuous meat consumption. In analysing my three chosen texts using both masculinity and feminist theory and research undertaken into the role of the cookbook more generally, I demonstrate that these examples employ narrative features that typify the cookbook, while at the same time presenting food choices that go against the grain of hegemonic genre expectation.

Before I begin this analysis, it is necessary to define certain words and phrases that I will be using. First, while I refer broadly to "vegan" or "plant-based" cookbooks, there is a discernible and important distinction between veganism as a lifestyle choice and plantbased eating as a purely dietary concern. The Vegan Society of the UK defines veganism as "a way of living that seeks to exclude, as far as is possible and practicable, all forms of exploitation of, or cruelty to, animals for food, clothing or any other purpose" (The Vegan Society 2020). A plant-based diet, on the other hand, while involving the exclusion of food derived from animal products, does not automatically indicate or require the avoidance of animal products in other areas such as clothing. Veganism, then, requires a commitment to the minimisation of the exploitation of animals through consumer choices including, but not limited to, food and drink. Concern for animal welfare is therefore a requisite element of veganism. On the other hand, the increasingly popular "plant-based diet" involves making "vegan" food choices, but does not necessarily imply non-exploitative consumer choices in other areas such as clothing or household products. Reasons for pursuing a plant-based diet are frequently more focused on broader environmental concerns and personal health and improvement, while veganism, by definition, requires engagement with the ethical question of animal exploitation. As the analysis in this article will demonstrate, this is an important distinction when trying to understand the importance of animal welfare and rights as motivation in discourses of veganism and plant-based eating, particularly when navigating male meat and dairy avoidance, and it has a considerable influence on the narrative voice used to convey information in vegan or plant-based cookbooks, including those authored by men. In the three cookbooks I have chosen to analyse, the level of engagement with 
veganism as a lifestyle as opposed to plant-based eating as a purely dietary choice varies. The cookbooks in question are, at a minimum, made up entirely of plant-based recipes and ostensibly aimed at audiences either already eating a plant-based diet or living vegan, or those considering making the change to one or the other.

The three cookbooks analysed here were all published to the UK market in 2018. The decision to analyse examples from the same year of publication enables the development of a clearer picture of vegan and plant-based cookbook narratives at a particular point in time. It is not the case that these cookbooks were necessarily intended solely for a UK audience, or that they were or are only available in the UK. Similarly, it is not the case that all the authors, contributors or publishers involved are British or UK-based themselves. My analysis is qualitative in scope, involving as it does close textual analysis of a small sample of cookbooks. In highlighting these three widely available, well-publicised and popular examples, I am not suggesting that it is impossible to find examples of male-authored vegan or plant-based cookbooks that differ from these examples. Rather, I highlight some of the commonalities between the three examples, and suggest what these commonalities might begin to tell us about broader societal challenges and anxieties relating to masculine identity, plant-based eating and veganism in the UK.

\section{The Role of the Cookbook}

Historically, the intended audience for the cookbook has typically been female. As Neuhaus (1999) has pointed out, the purpose of the early to mid-twentieth century cookbook was instructional, intended to guide women in caring for home, husband and children, and to re-establish and reify gender roles that had been socio-culturally and socio-politically problematised through the course of two world wars. These cookbooks were not simply about preparing satisfying meals - they also took on an aspirational role in the creation and reinforcement of socially prescribed, gender normative spaces.

In many respects, the twenty-first century cookbook marketed at women hasn't altered significantly from the post-war model. Jovanovski (2017: 105) notes that "cookbooks written by female food celebrities are publicised for their wholesome qualities, encouraging women to adopt nurturing qualities through food". Culver (2012: 33) considers the role of recognisable personas in compelling cookbook writing, asserting that "reading cookbooks does not necessarily translate to using them in the kitchen", and that it is "narrative qualities particularly sequence, description and voice" that form a large part of their appeal. Culver uses cookbooks by celebrity chefs Elizabeth David and Nigella Lawson as examples to illustrate how cookbooks occupy the space of the aspirational, the identity-forming and the identityvindicating. Regarded from this perspective, it stands to reason that books on the subject will transcend the purely practical or instructional. Culver (2012: 33-34) goes on to note how cookbooks "evolved from household manuals to lavishly presented aspirational texts over the course of the twentieth century", and that the biggest success stories in the genre "have been those that move beyond the simple question of how to cook, instead weaving stories, memories, and tantalising imagery among their recipes". Culver's (2012) focus is on how certain structural and narrative choices are consciously intended to appeal to women readers, 
through the collection of an (female) author's experiences and anecdotes to form a "self" that is relatable to the target market.

It would seem, however, that a male voice in cookbook authorship can make for a very different finished product. Insofar as masculinity is present in the process of cooking and serving food, it is marked out by perfectionism and professionalisation, and by the difference between the amateur "cook" hurriedly feeding her family, and the artistic, often mercurial chef - the man who leads and dominates within professional kitchens. Julier and Lindenfeld sum up this phenomenon - "The message is: Unless they're chefs, straight guys, especially single straight guys, can't cook" (2005: 2). While the aspirational cookbook aimed at the woman reader often signals a hegemonic femininity characterised by nurturing and care-giving, cookbooks by male authors which give "permission" for men to cook often do so in the language of hegemonic masculinity. They assert not that it isn't important to be manly, the hegemonic, idealised concept of manliness remaining intact and uninterrogated, but that it can be manly to cook. This is not to suggest that there is a complete lack of subversion, however. Vester (2020), for example, has suggested that while the historical context of cookbooks is a road map for gender and heteronormativity, some cookbook writers have "queered" the cookbook genre, satirising and subverting the traditional way in which cookbooks were used as mechanisms to mark out the parameters of "gender done properly". Despite these compelling subversions, however, those traditional, hegemonic gender frameworks still persist as a means of making the cookbook narrative recognisable, and furnishing it with an aspirational quality. In the analyses that follow, I demonstrate some of the ways in which this applies to male-authored vegan and plant-based cookbooks.

Julier and Lindenfeld expand further on the gender politics of cooking as practice, pointing out that "men predominate" in "professional cooking" (2005: 5), as distinct from the domestic sphere which entails caring and nourishment of the collective family and is marked out as women's work. The professionalisation of men's presence in the kitchen is at the heart of what Julier and Lindenfeld call "the male chef/female domestic cook dichotomy" (2005: 12) hinted at above. That which is, very broadly, the same act the cooking and serving of food - is done in very different ways in the contexts of hegemonic gender performance. The continued predominance of male celebrity chefs who foreground traditionally hegemonic masculine ideals and behaviours speaks in a very visible way to this. Julier and Lindenfeld, for example, note that "Anthony Bourdain names playing with knives and displaying burn scars as rites of passage into both manhood and a profession" (2005: 15). Nilsson (2013) discusses the role of "manliness" as the prized trait in running a successful kitchen, and how celebrity chef Gordon Ramsay, in his television show Hell's Kitchen, instils a practice, deeply rooted in humiliation and feminisation-as-punishment, which rewards cooperation with hegemonic masculinity in an environment where he himself is always, and must always be recognised as, the ultimate masculine hegemon. This demonstrates that, while it may be the case that historically the cookbook is an object that marks out hegemonic femininity, the professionalisation of cooking has created environments that are hostile to femininity and require, or claim to require, traditionally masculine traits for the individual chef to succeed. In my own analysis, I question the extent to which vegan and plant-based cookbooks authored by men "form a communicative bridge to readers' 
own aspirations or nostalgia" (Culver 2012: 40) in the way that the cookbook traditionally has. Following Culver's (2012) model, I consider the principles of sequence, description and voice, demonstrating ways in which certain structural and narrative choices have been made and highlighting how certain masculine social types are reified and compromises made with hegemonic masculinity.

I have demonstrated that cookbooks are not neutral and never have been - they have always been created from a specific perspective, with a resultant appeal to a certain gaze which is always gendered. In order to offer a properly contextualised analysis of these cookbooks, it is also necessary to understand the uneasy relationship between veganism and the plant-based diet on one hand, and hegemonic masculinity on the other.

\section{Vegan Masculinities}

If male writers of cookbooks are sometimes compelled to present their narrative in a compensatorily masculinised and professionalised way, the presence of veganism - or, as we will see, the absence of meat-eating - muddies the waters of masculinity in the cookbook still further. In the foregoing discussion, the term "hegemonic masculinity" has been used to describe the rhetorical approaches of male celebrity chefs. Connell $(2000,2005)$ and Connell and Messerschmidt (2005) have theorised hegemonic masculinity in depth, broadly defining it as a form of masculinity where power rests, and with which other forms of masculinity, including marginalised, complicit and subordinated masculinities, are in constant negotiation and dialogue. Hegemonic masculinity is not to be understood as the masculinity that most men live in their daily lives. Rather it is a notional ideal, a position held by a very small number of men, but that rewards other complicit masculinities in the form of a "patriarchal dividend" (Connell 2005). In other words, hegemonic masculinity may be best understood as an aspiration. In this section, I describe the ways in which hegemonic masculinity also marks out the persistent linkage of masculinity and meat.

In Outrageous Acts and Everyday Rebellions (1983: 191-196), Gloria Steinem dedicates a chapter to "Food and Politics", in which she points out that all over the world, men are considered to need more food, and that "for much of the female half of the world, food is the first signal of our inferiority" (1983: 191). More specifically, Steinem talks about traditions where the men of a family have been, or still are, served first, and served better quality food, with a particular focus on red meat, poultry, fish and other animal-derived products. These are circumstances in which meat is codified as the best type of food, and as a male preserve. In fact, meat as a symbol becomes an intrinsic part of masculinity in its hegemonic mode, and meat-avoidance as a "failure" to meet, or even a failure to be complicit in pursuing, that prescribed ideal. Julier and Lindenfeld (2005: 8) ask why the specific act of cooking meat on a barbecue is regarded as "the quintessential male domestic activity", suggesting that "this understanding assumes a fixed, invariable conceptualization of masculinity, rather than one that is permeable, fluid and changing". The problem with this assertion relates to Connell's $(2005,2000)$ model of hegemonic masculinity, which explains that while masculinities are indeed many, varied and ever-changing, a hegemonic form or forms can always be identified, and that form prescribes the terms under which "proper" 
masculinity is to be done. The point is not, in fact, that all men do this, or are even assumed to do this, but that they should aspire to it as a kind of zenith of masculinity.

The connection between masculinity and meat is well-documented. Adams, in The Sexual Politics of Meat (2015), elaborated on this in a work which would become seminal in the field, describing how the feminisation of animals and the animalisation of women intersected in the male gaze and in male consumption both of animals as meat and of women as sexual objects. Neuhaus (1999: 538), in an examination of US cookbooks of the 1950s, also treats this subject in respect of cooking, describing how cookbooks of the time could often be observed "linking masculine behaviour to meat preparation and barbecuing". Neuhaus (1999: 541-542) goes on to explain that this cooking of meat outdoors was generally the isolated example of men being encouraged to take on responsibility for cooking, and that this was certainly not symbolic of a more general willingness on the part of men to take responsibility for cooking indoors, or indeed for the preparation of anything that wasn't flesh. Indeed, Neuhaus (1999: 541) states that cookbook authors of the time "avoided the possibility that Dad may have been assuming daily cooking duties and concentrated on the fact that men and meat naturally belonged together" (original emphasis). Sobal (2005: 144) concurs, even in reference to men of the early twenty-first century, asserting that "when men do cook, it is often in the form of a hypermasculine display of meat preparation", and comparing the usefulness of single masculinities and multiple masculinities approaches in analysis of men's relationship with meat. Some of the multiple "scripts" of masculinity mentioned by Sobal include "the strong men", "the sensitive men" and "the wealthy men", and Sobal acknowledges that these multiple scripts of masculinity can take both hegemonic and "secondary" roles (2005: 146-147). This is consonant with Connell's (2000, 2005) theorising of hegemonic masculinity as previously discussed. While Sobal's analysis tends towards a false dichotomy of the "married" man as opposed to the single man, ostensibly neglecting, for example, the cohabiting man, it does offer very helpful reflections on how multiple masculinities can be embodied by men in different situations - that while hegemonic masculinity is ever-present, it is not the lived reality for many men. It is to this theory of alternative and co-existing scripts of masculinity, in dialectical relationship with hegemonic forms of masculinity, that I turn in my own analysis. Interestingly, Sobal (2005: 139) makes reference to the power of independence in food choice among men, and that "manly eating often represents a refusal to surrender food choices to authorities (including governmental, medical and spousal)". We can envisage this in the context of men eating large amounts of red meat as a form of rebellion against governmental advice, doctor's orders or even "wifely nagging". However, it is also revealing to consider this same rebellion in terms of what it means for men who choose veganism as a counter-culture. For example, might some men choose veganism, or at least plant-based diets, to reject the power of fast food advertising, or even traditional notions of the masculine meat-eater?

Sobal (2005: 140-141) notes how men engaging in meat avoidance seek to offer explanations for this decision that distance them from it. Where men are engaged in meat avoidance, which as we have seen is persistently coded as a lack of masculinity, they feel the need to present reasons for this avoidance - the examples offered by Sobal include not wanting to get barbecue sauce stains on a shirt before a meeting and "my wife packed 
sandwiches with no meat" (2005: 140). The point here, says Sobal, is that because vegetarian or vegan men are read as being in contravention of gender norms, the way they navigate their masculinity is potentially far more complex and fraught. In essence, "hegemonic masculinity provides a comparison point that individuals may elect to adopt or reject in specific places, times and relationships" (Sobal 2005: 147). There are, then, multiple scripts of masculinity in dialogue with hegemonic masculinity at any given point, and it is important to understand masculinity in general as contextual and variable. In writing within the traditionally feminine genre of the cookbook, without the traditionally masculinecoded "buffer" provided by the symbolism of meat, we can see that the male author of the vegan or plant-based cookbook must navigate two distinct but intersecting subversions of hegemonic masculinity.

The growing popularity, and mediatisation, of plant-based diets and vegan lifestyles has influenced, and been influenced by, discussions about men's health and fitness, and idealised male bodies. Julier and Lindenfeld agree, pointing out that:

The discourses of food and bodybuilding converge in the desire to control and manage the material body ... Abstracted from actual gyms or clubs, the discourse still reinforces a separate male prerogative surrounding nourishment, one that limits cooking to "popping some supplements" and "opening cans" (2005: 11).

As the textual analyses below demonstrate, the notion of vegan and plant-based cooking as fuelling the machine of masculine physicality can in fact be observed in male-authored vegan and plant-based cookbooks in a way that often echoes more traditional discourses of men, meat and protein. Vegan masculinities, just like meat-eating masculinities, are often founded on the rhetoric of health more than that of the environment or animal welfare and rights. After all, caring and nurturing have traditionally been coded as hegemonically feminine traits, and a signifier of effeminacy and aberration in men. This is a theme writ large in the documentary film The Game Changers (2018), in which director Louie Psihoyos presents UFC fighter James Wilks meeting a range of world class athletes, the vast majority of them men, who are "powered" entirely by a plant-based diet. The film features several "tests" of the true masculinity of men who eat plant-based diets - tests so mired in traditional and hegemonic masculine symbolism that they even extend to comparisons of penis size. It is striking that this film was released in UK cinemas in the same year that the three vegan cookbooks analysed below were released to the UK book market. This, I suggest, further reinforces how prominent veganism and plant-based diets were in UK media in 2018 and, furthermore, the extent to which meat and dairy avoidance were being marketed to a male audience not in spite of hegemonic masculinity, but complementary to it.

Interestingly, meat as a "men's product" entails a spectrum of specific food items that in turn suggest ceremony and ritual. Carol J. Adams' Burger (2018) offers a concise but detailed description of the burger as cultural object, a symbol of the post-war patriotic and nationalistic, particularly in the United States. Moreover, Adams' discussion reveals the kind of defensive response that vegetarian and "fake-meat" versions of the burger have elicited, particularly among those who view the burger as significant to their construction of both national and gender identities. This is reminiscent of Roland Barthes' Steak 
and Chips, where the significance of steak as a national symbol in France is expounded - "it follows the index of patriotic values: it helps them to rise in wartime, it is the very flesh of the French soldier..." (2009: 70). The link between the meat - in this case steak and national military prowess is richly evocative. Understanding patriotism and nationalistic sentiments as prized hegemonic masculine traits, and meat as a symbol of these traits, helps us to grasp what is regarded as the "lack" in masculine meat-avoidance. This, then, represents still further challenges for the male-authored vegan or plant-based cookbook, as the perceived threat of male meat-avoidance and subversion of masculine ideals extends even to matters of national identity, security and belonging.

As previously intimated, the cookbook in general also taps into the power of celebrity. In the examples that follow, the degree and nature of the celebrity of the author(s) varies. However, the power of celebrity that is both brought to and enhanced by the publication of a "personality" cookbook should not be underestimated. Persona and voice are vitally important in cookbook construction and marketing. There is certainly evidence that the early twenty-first century has seen a growing trend towards cookery-based TV programming in the United States that is geared towards the male viewer (Mitchell 2010: 524). One needn't look too hard in the UK to see that male celebrities - whether professional chefs or not - are saleable personas for cookery shows and cookbooks. Gordon Ramsay and Jamie Oliver, for example, are household names with bestselling books and TV shows that evidence their broad appeal. However, "the best-selling cookbooks come from professional and selftaught cooks alike" (Mitchell 2010: 525) and, as will be demonstrated in the analysis below, celebrities drawn from beyond the field of professionalised chefs are still a highly marketable feature of the vegan or plant-based cookbook authored by men. In a 2010 study of five cookbooks authored by a mix of professional chefs and popular amateurs alike, Mitchell (2010) identified a stark difference in how both gender and degrees of professional training on the part of the authors influenced the narrative tone and structure of the cookbooks themselves. Mitchell discovered that, in general, women authors and those without professional training tended to demonstrate a greater emphasis on encouraging readers to learn and then develop recipes, and to contextualise the acts of cooking and eating collectively with friends and family. Male authors and those with professional backgrounds in the kitchen were far more likely to "ignore" the reader, focusing on anecdotes about themselves, often with only a tenuous relevance to the recipes, and a greater appeal to authority coupled with less of a focus on ease or adaptability of recipe. Cookbooks, including male-authored vegan or plant-based cookbooks, promote an ideal to be aspired to, and celebrity involvement or endorsement supports this narrative technique, and sets the tone of the cookbook right from the front cover.

There will not be scope in this article to offer an exhaustive review of equivalent cookbooks by men which have meat preparation as their focus - not least because these remain so much more numerous. However, it is useful to consider, albeit briefly, how such books are marketed and presented. Mitchell (2010: 529-530) reviews Bobby Flay's Boy Meets Grill (1999), a barbecue or "grilling" cookbook authored by Bobby Flay, in which Mitchell reflects that "Flay seems to have no interest in his audience, except that they get to know him". Mitchell also points out that plentiful colour photography (of the food 
being prepared rather than the chef preparing it) and asides offering optional hints and tips are markers of the truly accessible cookbook, while the less accessible versions lack photography, or prioritise photography of the famous chef rather than what the dish should look like, and demonstrate an almost monomaniacal narrative focus on anecdote. In Bobby Flay's case, endorsements come from "male celebrities who have no connection to cooking" (Mitchell 2010: 537). In this analysis, I begin to establish what happens to that marketability when meat is taken out of the equation, and what challenges veganism and plant-based diets present to "masculinising" the cookbook.

What can all of this tell us about vegan and plant-based cookbooks authored by men at the beginning of the twenty-first century? Neuhaus (1999) notes the use of certain language in those very few 1950s cookbooks that were aimed at men. The ingredient of choice was invariably meat, and 'adjectives like 'husky' and verbs like 'slosh,' 'clamp' and 'fling' indicated that this recipe was not for the faint-hearted" (Neuhaus 1999: 541). Neuhaus goes on to describe how these cookbooks were presented in such a way that they "firmly positioned men as creatures of strength and action, who did not fuss around the kitchen" and that this "offset the potential threat to gender norms a man's presence in the kitchen might have presented" (1999: 541). In other words, while cookbooks were understood to be "women's objects", narrative, voice and meat as that ever-symbolic ingredient could reconcile the cookbook with hegemonic masculinity. How, then, does a male-authored cookbook navigate the maze of masculinity when that symbol of manliness - meat - is absent? There is, as has been discussed, a climate of defensiveness around men, plant-based eating and veganism. In reviewing the examples that follow, I will discuss what we can learn about attitudes to men's veganism and plant-based diet choices, based on a necessarily brief assessment of what is asserted, defended and erased in these cookbooks as textual and media objects. The scripts of masculinity that are visible, and invisible, are very revealing, and the narrative techniques used to instil a masculine confidence in plant-based and vegan food choices tell us a great deal about the ways in which the link between plant-based diets, veganism and masculinity is conveyed rhetorically.

\section{The Wicked Healthy Cookbook (2018)}

This cookbook, written by brothers Chad and Derek Sarno with David Joachim and with a foreword by Hollywood film star and prominent vegan Woody Harrelson, takes the reader to the appeal to health before they've even cracked the spine of the book. The cover (see Figure 1) features the lower torso of a tattooed man brandishing a meat cleaver as he chops fresh beetroot, the juice of the beetroot (we are, presumably, to understand blood here) splashed dramatically on the blade but also on the plain white apron of the chef, which is itself evocative of a butcher's apron. The cover makes a bold statement - this book is not going to offer the gentle or the tender, and a man will still need his "serious" tools for the job. The cover, as well as evoking health without compromising on "wickedness", does place its "Free. From. Animals" message openly, but it remains difficult to avoid the compensatory nature of the cover image. 
Figure 1: Front cover of The Wicked Healthy Cookbook (2018) by Chad Sarno, Derek Sarno and David Joachim, cover image copyright Eva Kosmas Flores, design by Bekki Guyatt

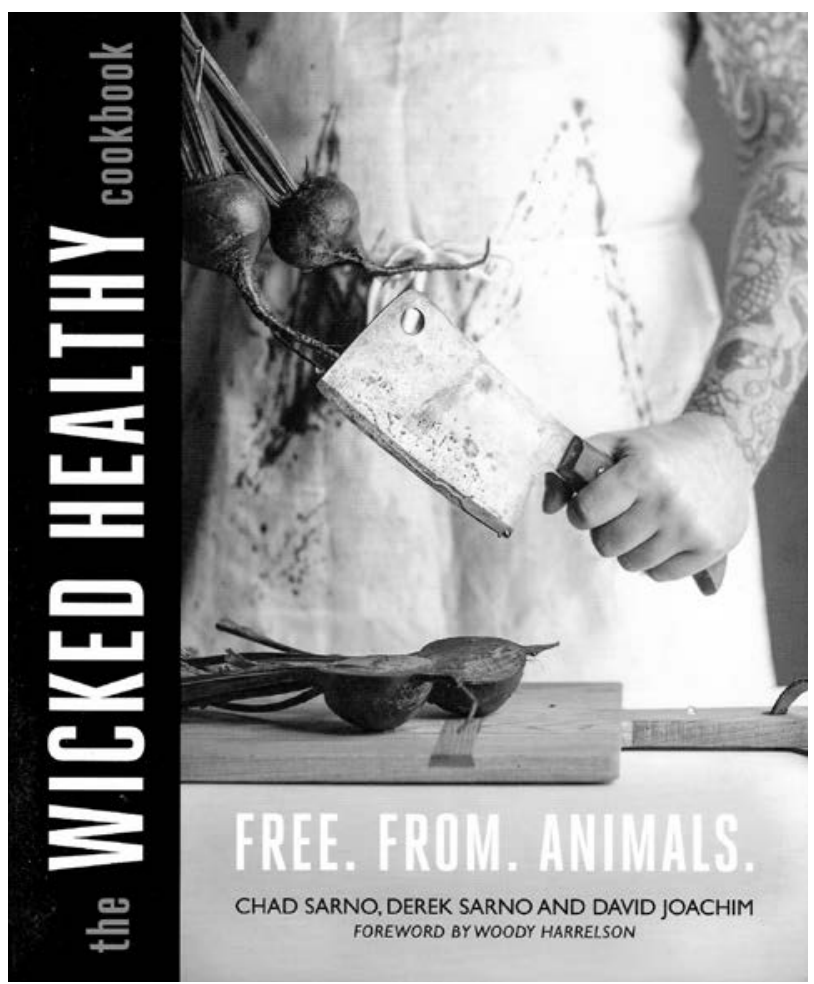

The choice and sequencing of the recipes has a focus on the casual meal - pizzas, dips, tacos, burgers and bowls are plentiful. Examples of section titles include "Handhelds", "First Bites" and "Straight-Up Vegetables", suggesting a focus on the easy and casual, on functional food for busy men. Harrelson's straight-talking foreword mentions that Chad Sarno was his personal chef on movie sets in the past, and that "these guys will teach you how to make your meals taste amazing ... . healthy food doesn't have to taste like shit", while also reassuring the non-vegan that "this food is for everybody. It is just good, sexy food anyone would love" (2018: xi). This three-pronged appeal to simplicity, taste and health sets the tone for the book itself - despite the animal free message of the spine, the reader is led to believe that the nonvegan is not going to be made to feel guilty or emasculated here, and "sexiness" is front and centre. The introduction, written by Chad and Derek Sarno, is titled "Diet, Schmiet" going on to reassure the reader that, while the book is intended to promote health ("because healthy people are full of life ... upbeat, confident and energetic"), taste is paramount (2018: xii). They claim to offer healthy eating that "is not about starvation or choking down food that tastes like shit" - the narrative of the book in general seems defensive about the common notion that plant-based food is tasteless, or "tastes like shit". The dubious implication here 
is that appealing plant-based food is a novelty, and that the authors are the ones to deliver it. The Sarno brothers reassure the reader that they're "plant-pushers, not meat shamers!", distancing their narrative from veganism as a lifestyle commitment in favour of plant-based health that just happens to be good for the planet. The concept of "dieting" is only brought into the narrative defensively - to reassure the reader that this really isn't a diet book. The Sarno brothers are professional chefs, and the book's rhetorical approach involves appealing to this expertise but with a focus on simplicity and "no-nonsense" cooking. The first 49 pages are given over to personal anecdote, with some reflections on the journey to plant-based eating; however, this introductory section does contain practical advice on cooking methods and shopping efficiently. There are several full-page photographs of the authors throughout the book, most featuring them eating or shopping for produce. Colour photographs of the dishes themselves are frequent.

The Wicked Healthy Cookbook maintains a focus on health throughout, but the resistance to stereotypical "diet" narratives is persistent. It is clearly important to the authors that traditional diet narratives that gravitate to feminised language and body policing are swapped out for the language of proper fuelling of the body as organic machine. The "way of doing" masculinity in this cookbook rejects the idea that meat-eating is necessary for masculinity, narratively compensating by changing the rhetoric of dieting for health into "fuelling", rather than the traditionally more feminised language of restriction. There is a distinct focus on the personalities of the authors who are professional chefs, including through photography and appeals to professional authority. I suggest that the focus of this cookbook is on plantbased eating rather than veganism as a lifestyle, and that the script of choice generally glosses over the ethical questions of veganism in favour of the health benefits of a plantbased diet. If anything or anyone is being nurtured here, it is the individual masculine body, with a narrative voice that is individualistic rather than the family-focused style of traditional family cookbooks. The Wicked Healthy Cookbook is generally engaged in reconciling plantbased eating with traditional notions of masculinity. The overall message is a defensive one; that plant-based eating needn't be feminising, and that the focus is on bodily strengthening rather than reducing.

\section{BOSH! (2018)}

This cookbook is touted as a companion to "BOSH!, the biggest plant-based online channel in the world" (2018: 8). The book sees friends Henry Firth and Ian Theasby present recipes under such pared-down chapter titles as "Quick Eats", "Big Eats" and "Greens \& BOSH! Bowls". The cover (see Figure 2) features colour photographs of some of the dishes, with a small testimonial from celebrity chefs The Hairy Bikers, who are themselves noted for having recently expanded into "diet" and then vegetarian cookery after several years of specialising in indulgent dishes with a heavy focus on meat. In their introduction, Firth and Theasby assert that "the concept of cooking without meat and dairy is still relatively new" (2018: 7) which, as noted above, is not at all accurate, and fails to adequately address the roots of much plantbased and vegan food in non-Eurocentric contexts and cultures. From the outset their focus is on "plant-based eating", catering to both the established plant-based eater and meat-eaters 
alike, with recourse to "hearty, even indulgent meals" and "fail-safe family favourites" (2018: 7). The introduction is accompanied by a full-page photograph of Firth and Theasby posing with bowls full of food. Theasby and Firth have both gone from regular meat-eaters to plant-based food chefs, and stress the "novelty" and "wow factor" of their "new style of cooking" - and they are less than complimentary about some of the vegan restaurants and cookbooks that came before them (2018: 8). Throughout the introductory material, Firth and Theasby insist upon the novelty and originality of their approach to plant-based cooking. There is also a narrative tone that inclines to the professionalised and perfectionist style of the male-authored cookbook noted above. Firth and Theasby caution the reader that "these recipes work to a level that many in other cookbooks do not" and "these are high-quality recipes", promising both "fast food fast" and "showstoppers" (2018: 10). The narrative is frequently confused and contradictory on the question of whether this provides simple, no-fuss food to fuel the body, or cuisine to showcase professionalised expertise.

Figure 2: Front cover of BOSH! (2018) by Henry Firth and Ian Theasby, photography copyright Lizzie Mayson

\section{SIMPLE RECIPES} AMAZING FOOD ALL PLANTS

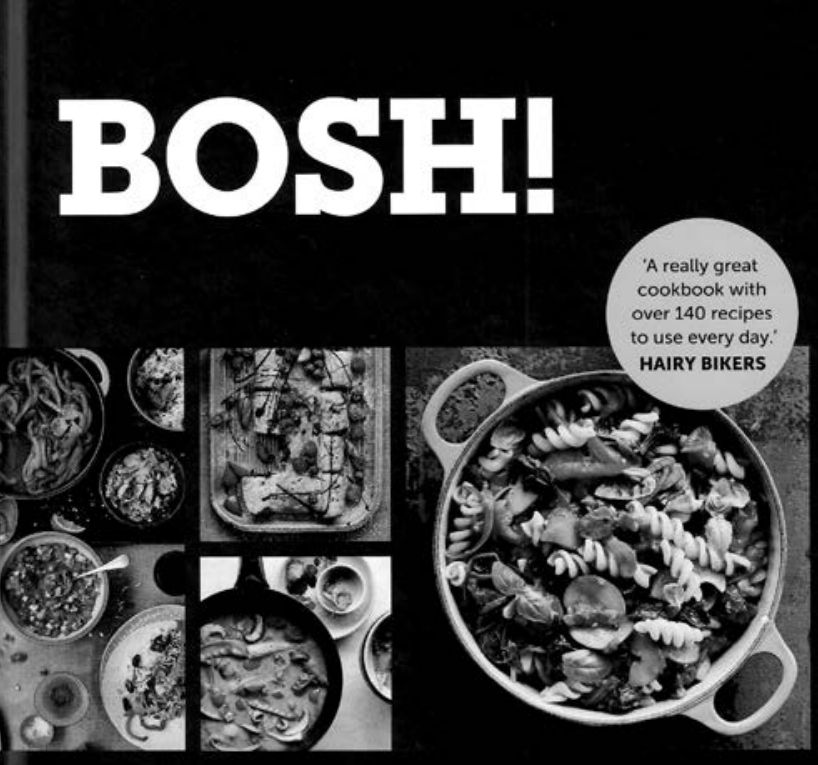

HENRY FIRTH \& IAN THEASBY 
The narrative script of masculinity in this cookbook would seem to favour the hegemonic authority of expertise espoused by male celebrity chefs as detailed above - there is an insistence on the novelty of the fare and techniques that isn't always evidenced by the recipes themselves. The title, BOSH!, calls to mind Neuhaus' remarks about earlier cookbooks aimed at men, wherein words like "slosh" and "fling" are employed to convey the image of the strong man in the kitchen (1999: 541). The script of masculinity and health that was so prominent in The Wicked Healthy Cookbook is far less prominent in this example. Instead, we can observe a narrative that appeals to a taste for simple food and casual eating, but characterised by contradiction - the reader is encouraged to "get the right kit" (2018: 10) but later reassured that "the equipment you find in your typical kitchen is going to work just fine for the recipes in this book" (2018: 14). I would suggest that this cookbook represents an example of narrative styles and authorial voices engaged in a confused rhetoric in its attempt to reconcile plant-based food and masculinity within the traditional cookbook narrative. As is the case with The Wicked Healthy Cookbook, the ethical elements of veganism such as animal rights are not at the forefront. In this case, cooking expertise and successfully following the recipe seem to decentre the ethical focus.

\section{Dirty Vegan (2018)}

"Proper banging vegan food" is promised by this cookbook by Matt Pritchard (see Figure 3). Pritchard is famous as a member of the Dirty Sanchez team, who were the subject of several TV series in the early to mid-2000s, built around pranks and stunts. This is certainly the persona that drives the narrative of this cookbook, which is interspersed with frequent photographs of Pritchard in action poses, all taken at a skatepark under a motorway flyover. Full colour photographs of the dishes are frequent, but it is noteworthy that Pritchard is not photographed eating or cooking them - photographs of him as author are limited to these skateboarding action shots. The introductions to each recipe are largely focused on the recipe itself, though each section - these include "Morning Kick-Start", "Quick Hits and Gobfuls" and "The Main's Best Mate" - is introduced with a brief authorial anecdote alongside the action shots of Pritchard. In "Pritch's Preface", Pritchard opens with his mission statement for the book - he's aiming the "a bit no-nonsense" recipes at new vegans who want "simple ideas for some tasty grub" (2018: 6). Throughout the book, the voice is informal, with phrases and expressions ("tasty grub", "banging food") and recipes such as "The Full Hangover Pile-Up" (2018: 25) and "Smack-You-In-The-Face Smoothie" (2018: 39) that lend the options a down-to-earth, familiar and even rebellious tone. Pritchard locates the cookbook's narrative in a distinctly counter-cultural script, and the implication of a form of rebellious masculinity again fails to properly acknowledge the roots of veganism, instead presenting it as something of a novelty or departure. He isn't noticeably focused on the health script for veganism or plant-based diets - in the preface he reassures the reader that "this type of diet definitely isn't just for athletes" (2018: 6) - and the voice is consciously down-to earth, as he informs the reader that "cookbooks can be really intimidating. I hope this one isn't" (2018: 6). He admits that he has sought help from a professional chef, Rob Andrew, to compile the recipes, and pages 9 to 13 are taken up with Pritchard's journey to veganism. 
This throws into relief the power of celebrity persona - with or without culinary expertise in marketing cookbooks to certain readers. Fans of Pritchard or Dirty Sanchez may pick up this book at a bookseller, but it's not altogether clear that they would do so if they were simply seeking out Rob Andrew's recipes, which I suggest implies that the intended audience is largely of the counter-cultural yet arguably complicit masculinity implied by Pritchard's celebrity persona. What is clear is that, for Pritchard, this is not just a plant-based cookbook but a guide to being male and vegan - he subverts the prescriptions of hegemonic masculinity and meat-eating when he makes clear in the introduction that animal welfare was the major driver of his choice to go vegan (2018: 12-13). Nevertheless, there is an image and narrative technique at work in the book that presents veganism-as-machismo; something new rather than something with its own cultural contexts and meanings that predate Pritchard's own iteration of it.

Figure 3: Front cover of Dirty Vegan (2018) by Matt Pritchard, cover illustrator Andy Smith

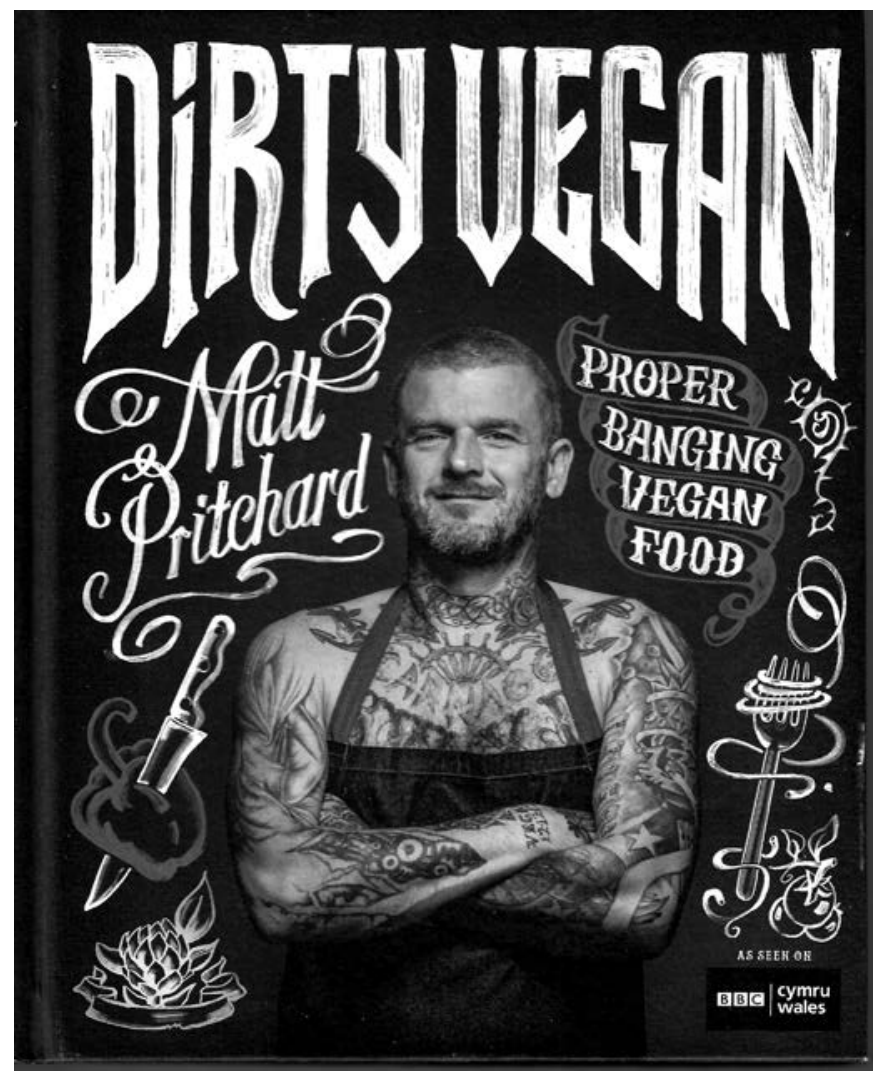




\section{Conclusion}

These three examples of male-authored vegan or plant-based cookbooks share commonalities that reveal how male meat and dairy avoidance refigure and reconcile with hegemonic masculinity, and with masculinities that are complicit with and marginalised by it. These are examples which demonstrate a trend for using at least some of the "tools" of hegemonic masculinity to promote meat-avoidance, particularly in design, author characterisation and narrative voice. I suggest that the question of animal rights and welfare is frequently elided or side-lined, and that this occurs because the theme of personal improvement is considered less feminised and contentious in terms of the construction of masculinity even where that masculinity is being posited as counter-cultural - than that of animal exploitation. These cookbooks largely locate food as a personal rather than political choice, whereas a truly vegan cookbook must contend with questions of ethics and antioppression while acknowledging the theoretical and practical roots of the philosophies being deployed to sell copies. These three examples of vegan and plant-based cookbooks written by men and released to the UK market in 2018 do not, of course, represent anything like the whole story of vegan cookbooks. Indeed, while a comparison with other vegan or plant-based cookbooks authored by women or male-authored cookbooks focused on meat hasn't been within the scope of this article, such a comparison would no doubt be useful and illuminating. The case studies do, however, speak to something of a zeitgeist for veganism in the media and in corporate marketing more generally, which currently shows no sign of abating, and to some commonalities of approach that reveal some of the techniques being used to market the plant-based diet to men. Connell's $(2000,2005)$ theory of the hegemonic masculine provides us with a useful reference point, from which it is possible to compare and contrast how variant forms of masculinities enter into dialectical relationship, and how movements such as plant-based eating or veganism can be observed engaging in complicity in an attempt to reconfigure what we mean by "a real man". I argue that, in all of these cookbooks, resistance to meat-eating is fraught with limits and circumscribed with caveats. I suggest that this is an interesting marketing decision, involving a compromise with the idea of an idealised, hegemonic model of masculinity to which it is necessary to aspire, or at least attempt to reconfigure so that plant-based eating and veganism can be adopted as hegemonic. In the case of these cookbooks, it is not the concept of an ideal masculinity that is interrogated, simply what that masculinity ought to look like - and the suggestion is that hegemonic masculinity can be reconfigured to be plant-based and not meat-eating. There is a persistent insistence upon the novelty of the diet being marketed by these cookbooks that neglects the far older and broader context of plant-based eating and veganism and their non-Eurocentric roots. The existence of books on this topic by women and people of colour which predate these volumes is largely ignored in a way that could lead the general reader to conclude that plant-based eating and even veganism are recent, Western, masculine inventions. I suggest that it is the necessity of meat for hegemonic or ideal masculinity, and not the masculinity itself, that is interrogated in these three cookbooks. 


\section{References}

Adams, Carol J. 2018. Burger: Object Lessons. New York: Bloomsbury.

Adams, Carol J. 2015. The Sexual Politics of Meat: A Feminist-Vegetarian Critical Theory. New York: Bloomsbury.

Barthes, Roland. 2009. Mythologies. Translated from the French by Annette Lavers. London: Vintage.

Breeze Harper, A. 2011. "Connections: Speciesism, Racism and Whiteness as the Norm." Pp. 72-78 in Sister Species: Women, Animals and Social Justice, edited by Lisa Kemmerer. Urbana: University of Illinois Press.

Coghlan, J. Michelle. 2020. "Chronology of Major Works and Events.” Pp. xiii-xxiii in The Cambridge Companion to Literature and Food, edited by J. Michelle Coghlan. Cambridge: Cambridge University Press.

Connell, R. W. 2000. The Men and the Boys. Cambridge: Polity Press.

Connell, R. W. 2005. Masculinities. $2^{\text {nd }}$ Edition. Cambridge: Polity Press.

Connell, R. W. and James W. Messerschmidt. 2005. "Hegemonic Masculinity: Rethinking the Concept." Gender and Society 19(6): 829-859.

Culver, Carody. 2012. "A Pinch of Salt and a Dash of Plot: The Power of Narrative in Contemporary Cookbooks." Journal of the Australasian Universities Language and Literature Association 118: 3350.

Firth, Henry and Ian Theasby. 2018. BOSH!. London: HQ.

Fisher, Linda. 2011. "Freeing Feathered Spirits." Pp. 110-116 in Sister Species: Women, Animals and Social Justice, edited by Lisa Kemmerer. Urbana: University of Illinois Press.

Flay, Bobby. 1999. Boy Meets Grill. New York: Hyperion.

Jovanovski, Natalie. 2017. Digesting Femininities: The Feminist Politics of Contemporary Food Culture. London: Palgrave Macmillan.

Julier, Alice and Laura Lindenfeld. 2005. "Mapping Men onto the Menu: Masculinities and Food." Food and Foodways: Explorations in the History and Culture of Human Nourishment 13(1-2): 1-16.

Mitchell, Christine M. 2010. "The Rhetoric of Celebrity Cookbooks." The Journal of Popular Culture 43(3): 524-539.

Nath, Jemál. 2010. "Gendered Fare?: A Qualitative Investigation of Alternative Food and Masculinities." Journal of Sociology 47(3): 261-278.

Neuhaus, Jessamyn. 1999. “The Way to a Man's Heart: Gender Roles, Domestic Ideology, and Cookbooks in the 1950s." Journal of Social History 32(3): 529-555.

Neuhaus, Jessamyn. 2012. Manly Meals and Mom's Home Cooking: Cookbooks and Gender in Modern America. Baltimore: John's Hopkins University Press.

Nilsson, Gabriella. 2013. "Balls Enough: Manliness and Legitimated Violence in Hell's Kitchen." Gender, Work and Organization 20(6): 647-663.

Pritchard, Matt. 2018. Dirty Vegan. London: Mitchell Beazley.

Raet, Iya. 2010. "Ma'at Diet." Pp.139-149 in Sistah Vegan: Black Female Vegans Speak on Food, Identity, Health and Society, edited by A. Breeze Harper. New York: Lantern.

Sarno, Chad, Derek Sarno, and David Joachim. 2018. The Wicked Healthy Cookbook. London: Sphere.

Sobal, Jeffery. 2005. "Men, Meat and Marriage: Models of Masculinity." Food and Foodways 13(1): 135158.

Spencer, Colin. 2016. Vegetarianism: A History. London: Grub Street.

Steinem, Gloria. 1983. Outrageous Acts and Everyday Rebellions. London: Fontana.

Stuart, Tristram. 2008. The Bloodless Revolution: A Cultural History of Vegetarianism from 1600 to Modern Times. London: W. W. Norton \& Company.

The Game Changers. 2018. Directed by L. Psihoyos. [Feature film]. USA: Refuel Productions. 
The Vegan Society. 2020. Definition of Veganism. Retrieved March 5, 2020 (https://www.vegansociety. com/go-vegan/definition-veganism).

Vester, Katharina. 2020. "Queering the Cookbook." Pp.131-145 in The Cambridge Companion to Literature and Food. Cambridge: Cambridge University Press.

Wright, Laura. 2015. The Vegan Studies Project: Food, Animals and Gender in the Age of Terror. Athens: The University of Georgia Press.

\section{Author}

Rebecca Jones is a PhD researcher in English at the University of Strathclyde, funded by a Student Excellence Award (SEA). Her research uses posthumanist and critical animal studies theory to analyse the links between species, meat and masculinity in speculative fiction since Frankenstein. Rebecca can be reached by email and on Twitter at @beckmjones. Contact: rebecca.jones@strath.ac.uk 